\title{
Impact of angiotensin receptor blocker product recalls on antihypertensive prescribing in Germany
}

\author{
Ulrike Maria Rudolph $\mathbb{1}^{1} \cdot$ Salka Enners $\mathbb{D}^{2} \cdot$ Marita Kieble $^{2} \cdot$ Felix Mahfoud $\mathbb{D}^{3} \cdot$ Michael Böhm $^{3} \cdot$ Ulrich Laufs ${ }^{1}$. \\ Martin Schulz $\mathbb{1}^{2,4,5}$
}

Received: 4 June 2020 / Revised: 8 August 2020 / Accepted: 28 September 2020 / Published online: 14 October 2020

(c) The Author(s) 2020. This article is published with open access

\begin{abstract}
In Germany, $~ 8$ million patients take angiotensin receptor blockers (ARBs) and 2.25 million of them valsartan. In 2018, contamination of generic ARBs with probable carcinogenic nitrosamines resulted in more than 30 recalls. The impact of such a huge recall has never been explored in Europe. We analyzed the utilization of valsartan, all ARBs, and other alternative antihypertensive drugs in Germany. We used our database of anonymized dispensing data from $>80 \%$ of community pharmacies at the expense of the statutory health insurance (SHI) funds from January 2017 to December 2019. We analyzed 290.8 million prescriptions, including all oral mono- and fixed-dose combinations of ARBs and plausible alternatives, i.e. ACE inhibitors (ACEi), beta-blockers (BB), and calcium channel blockers (CCB). Utilization was calculated by defined daily doses per 1000 SHI-insured persons per day (DID). Valsartan use decreased substantially after the recalls in July 2018 from 39.0 to 14.2 DID (-64\%) in the second quarter of 2019 and to 16.9 DID $(-57 \%)$ in the fourth quarter of 2019. Simultaneously, the use of alternative ARBs increased from 77.7 DID in the second quarter of 2018 to 121.9 DID $(+57 \%)$ in the fourth quarter of 2019, mainly due to an increase of candesartan dispensing to 99.8 DID (+73\%). There were no changes in the utilization of ACEi, BB, or CCB. The majority of recalled generic valsartan products were replaced by other ARBs, predominantly candesartan, despite documented drug shortages. In contrast to previous safety warnings/recalls, our data do not suggest an under-prescription of antihypertensives during this period.
\end{abstract}

\section{Introduction}

Angiotensin receptor blockers (ARBs) are the most commonly used drugs for the treatment of arterial hypertension, heart failure, and chronic kidney disease [1]. In Germany, $\sim 8$ million patients take ARBs and 2.25 million of them valsartan [2].

Ulrike Maria Rudolph

Ulrike.Rudolph@medizin.uni-leipzig.de

1 Department of Cardiology, University Hospital Leipzig, Leipzig, Germany

2 German Institute for Drug Use Evaluation, Berlin, Germany

3 Department of Internal Medicine III-Cardiology, Angiology and Intensive Care Medicine, Saarland University Medical Center, Homburg, Germany

4 Drug Commission of German Pharmacists, Berlin, Germany

5 Institute of Pharmacy, Freie Universität Berlin, Berlin, Germany
In accordance with the European Medicines Agency, the German Federal Institute for Drugs and Medical Devices announced recalls of generic valsartan products on July 4th, 2018 [3]. The drugs were recalled due to high concentrations of probable carcinogenic nitrosamines found in selected lots of ARB substances and generic drugs, primarily valsartan from Zhejiang Huahai Pharmaceutical Co., Ltd., Linhai, China. These impurities were most likely related to a change in the manufacturing process of the valsartan substance implemented in 2012 [4]. Subsequently, 16 marketing authorization holders recalled affected batches of more than 30 generic drugs containing impurities. Drug products from the originator and a couple of generic products utilizing valsartan from other production facilities were not recalled. Later recalls from August 2018 to March 2019 involved further generic valsartan products as well as generic irbesartan and losartan [5, 6]. Other manufacturers and other drug classes were recognized to be contaminated with nitrosamines and were recalled worldwide [5]. Previous safety warnings and medication recalls were associated with gaps in prescriptions and often 
associated with adverse health outcomes, also due to drug shortages [7-10].

To the best of our knowledge, the impact of this huge drug product recall on the further use of antihypertensive medication has never been explored in Europe. We, therefore, analyzed the utilization of valsartan, all ARBs, and other alternative antihypertensive drugs, that are angiotensin-converting enzyme inhibitors (ACEi), betablockers (BB), and calcium channel blockers (CCB) before and after the recalls in Germany.

\section{Methods}

This drug utilization study used the database of the German Institute for Drug Use Evaluation (DAPI) containing anonymous dispensing data of community pharmacies [11]. Data from a representative sample of more than $80 \%$ (until 06/2019) and more than 95\% (from 07/2019 onwards) of German community pharmacies were available. The data were extrapolated by regional factors to $100 \%$ of the population insured by the statutory health insurance (SHI) covering $88 \%$ of Germany's population. Until 06/2019 regional factors were calculated by dividing the number of community pharmacies by the number of pharmacies covered by the DAPI database in the respective region. From 07/2019 onwards, regional factors were calculated by dividing the number of dispensed packages reported by a federal information system about SHI-covered prescriptions known as GAmSi (GKV-Arzneimittel-Schnellinformation) [12] by dispensed packages in the DAPI database in the respective region. Prescriptions for privately insured patients are not covered by our database. Data on the indication, treatment duration, or dosages as well as data on individual patients were not available.

Using the specific product code (Pharmazentralnummer, an identification number for pharmaceutical products in Germany), dispensing data were linked to a database containing information on the brand/generic name, composition, active ingredients, package size, dosage form, and route of administration [13].

The dispensings of antihypertensives in Germany in the period from January 2017 to December 2019 were explored to illustrate the changes in utilization after the recalls in the second half of 2018. Apart from ARBs, we analyzed ACEi, $\mathrm{BB}$, and $\mathrm{CCB}$ as plausible alternatives as well as for comparison of dispensing data. Hence, all orally administered mono- and fixed-dose combinations containing the following drug classes were included: ARB, ACEi, BB, and CCB.

The allocation of the active ingredients was based on the official version of the Anatomical Therapeutic Chemical (ATC) classification system with defined daily doses (DDD) published by the German Institute of Medical Documentation and Information [14]. DDD are the assumed average daily maintenance dose for the main indication of a drug in adults [15]. Individual substances were analyzed according to the ATC code level 5. For the analysis of individual ARBs, we included mono preparations and combinations with hydrochlorothiazide only because those were affected by the recalls.

In Germany, antihypertensive drugs are usually dispensed in a 3-months' supply, that is in general 100 tablets in a norm size N3 drug package. It is possible to prescribe more than one drug package per prescription.

As the drug utilization unit, the DDD per 1000 inhabitants per day (DID) was used providing an estimate of the proportion of the population treated daily with a particular drug or group of drugs [15]. The DID is a global, technical unit used for evaluation of drug utilizations and treatment frequencies allowing comparisons across various time periods [16]. Compared to other measurement parameters, DID has the advantage that drug utilization is measured using a standardized amount of active ingredient. To adapt for the SHI-insured population analyzed, we calculated the DDD per 1000 SHI-insured persons per day. The numbers of SHI-insured persons were obtained from the Federal Ministry of Health [17].

We calculated moving averages per month regarding the respective month and the two previous months to smooth short-term fluctuations and highlight longer-term trends.

For the individual ARBs, we also observed the dispensed DID on a daily basis. To determine differences in the dispensing of 2018 compared with 2017 we divided the DID of the weekdays in June and July 2018, the month of first recalls, by the weekdays in June and July 2017. We excluded Sundays for better comparability.

DID ratio of matched weekdays $=\frac{\operatorname{DID}(2018)_{\text {of weekday } x}}{\operatorname{DID}(2017)_{\text {of weekday } x}}$.

To control for drug expenditures, health insurance funds are closing so-called rebate contracts with, above all, the generic pharmaceutical industry. These contracts require the pharmacist to dispense a specific generic drug product. The inability to fulfill rebate contracts of the SHI in the pharmacy due to unavailability of rebated drugs and the subsequent dispensing of a drug not rebated is documented by printing a specific code on the prescription [18]. The amount of prescriptions with this code was taken as an indicator for potential drug shortages.

\section{Results}

The analyses included 290.8 million prescriptions for antihypertensive drugs from January 2017 to December 2019 
Table 1 Number of prescriptions for antihypertensive drugs, dispensed drug packages, and drug packages per prescription 2017-2019.

\begin{tabular}{llll}
\hline $\begin{array}{l}\text { Year and } \\
\text { quarter }\end{array}$ & $\begin{array}{l}\text { AHT prescriptions } \\
\text { (million) }\end{array}$ & $\begin{array}{l}\text { Drug } \\
\text { packages } \\
\text { (million) }\end{array}$ & $\begin{array}{l}\text { Drug packages } \\
\text { per prescription }\end{array}$ \\
\hline 2017 Q1 & 23.6 & 28.9 & 1.22 \\
2017 Q2 & 23.9 & 29.4 & 1.24 \\
2017 Q3 & 23.6 & 29.0 & 1.23 \\
2017 Q4 & 24.4 & 30.0 & 1.23 \\
2018 Q1 & 23.9 & 29.4 & 1.23 \\
2018 Q2 & 24.4 & 30.0 & 1.23 \\
2018 Q3 & 23.9 & 29.2 & 1.22 \\
2018 Q4 & 24.6 & 30.2 & 1.23 \\
2019 Q1 & 24.0 & 29.4 & 1.22 \\
2019 Q2 & 24.7 & 30.3 & 1.22 \\
2019 Q3 & 24.5 & 30.1 & 1.23 \\
2019 Q4 & 25.2 & 31.0 & 1.22 \\
Total & 290.8 & 356.8 & 1.23 \\
Average per & 24.2 million & 29.7 million & 1.227 \\
quarter & & &
\end{tabular}

$A H T$ antihypertensive drugs, $Q$ quarter.

(Table 1). $47 \%$ of all included product codes of antihypertensive drugs were fixed-dosed combinations with $17 \%$ of total dispensings. Of these, $67 \%$ were combination products with hydrochlorothiazide with $80 \%$ of the dispensings of all combination products, and $49 \%$ were combinations containing ARBs and hydrochlorothiazide with $40 \%$ of the dispensings of all combination products.

The dispensings of valsartan products remained at a constant average level of 39.0 DID from January 2017 until June 2018 (Table 2, Figs. 1 and 2). After the first recalls of valsartan products in July 2018, dispensings decreased substantially and continuously to an average of 27.2 DID $(-30 \%)$ in the first quarter (Q1) of 2019 and subsequently to 14.2 DID (-64\%) in Q2 2019. Throughout the second half of 2019, valsartan dispensings remained low with 15.2 DID (-61\%) in Q3 2019 and 16.9 DID (-57\%) in Q4 2019 (Table 2; Fig. 1).

The market shares for generic valsartan products recalled in July and November 2018 were both $45 \%$ in the 3-month period prior to the respective recall. Before the first recall, non-recalled and recalled valsartan products together had a market share of $35 \%$ of all ARBs, which decreased to $26 \%$ $(-26 \%)$ in the second half of 2018 and to $12 \%(-66 \%)$ in the second half of 2019 .

With the decrease of valsartan, alternative ARBs increased by an average of 7.4 DID per quarter (from 77.7 DID in Q2 2018 to 121.9 DID (+57\%) in Q4 2019). Candesartan was the ARB with the largest increase in prescription (average increase of 7.0 DID per quarter from 57.7 DID in Q2 2018 to 99.8 DID $(+73 \%)$ in Q4 2019 (Fig. 1 and Table 2)).
For telmisartan, losartan, and olmesartan, only a slight increase of dispensing was observed (Table 2).

Before the first recalls in July 2018, the ratio of the matched daily dispensings for valsartan and candesartan predominantly showed values close to 1 , with the exception of public holidays. After the first recalls were instituted, the ratio initially increased to 1.43 for valsartan and 1.30 for candesartan, respectively. Afterwards, the ratio decreased substantially to 0.65 for valsartan while the values for candesartan reached 1.56-1.27 (Fig. 2).

For valsartan and candesartan mono and hydrochlorothiazide combinations, a substantial increase in the amount of prescriptions with documented unavailability of rebated drugs could be observed from July 2018 onwards (Fig. 3). For valsartan, the amount of documented unavailability increased from 2200 prescriptions in June 2018 to a peak of 242,400 prescriptions in January 2019 and subsequently decreased to 4900 in December 2019. For candesartan, the number increased steadily from 1400 in June 2018 to 406,100 in November 2019. In 2019, in total 2.2 million out of 14.9 million (15\%) dispensing processes of candesartan drug products were unavailable. For valsartan, in about 1.0 million out of 3.5 million (29\%) dispensings, drug products were unavailable.

There was no impact of the recalls on the moderate, but continuous increase of the total dispensing of all ARBs. Utilization of $\mathrm{ACEi}, \mathrm{BB}$, and $\mathrm{CCB}$ remained nearly unchanged (Fig. 4).

\section{Discussion}

The more than 30 recalls of generic drug products containing ARBs from July 2018 to March 2019 due to impurities with probable carcinogenic nitrosamines led to a rapid and substantial decrease in valsartan and a compensatory increase in candesartan dispensings, resulting in an increase in the total volume of ARB prescriptions from 2018 to 2019. Dispensings of $\mathrm{ACEi}, \mathrm{BB}$, and $\mathrm{CCB}$ remained nearly unchanged. The data, therefore, suggest that patients were primarily switched within the class of ARBs, mostly from valsartan to candesartan. Interestingly, and in contrast to other medication safety warnings/recalls and subsequent drug shortages, the data do not suggest an under-treatment on a population level during this period $[7-10,19]$.

Valsartan is a guideline-recommended drug for the treatment of hypertension and heart failure and is administered in cumulative daily doses of $80-320 \mathrm{mg}[20,21]$. Valsartan was patent-registered in 1991 and became generic in 2011. The market share of generic valsartan before the recalls was 35\% of all ARB in Germany. Prior to the generic valsartan recalls, candesartan was already the most frequently prescribed ARB with 57.7 DID, followed by valsartan with 39.0 DID. 
Table 2 Monthly dispensings of angiotensin receptor blockers in DID from January 2017 to December 2019.

\begin{tabular}{|c|c|c|c|c|c|c|c|c|c|}
\hline \multirow[b]{2}{*}{ Month } & \multicolumn{9}{|l|}{ DID } \\
\hline & Valsartan & Candesartan & Losartan & Telmisartan & Irbesartan & Olmesartan & Eprosartan & Azilsartan & All ARBs \\
\hline Jan 2017 & 36.9 & 50.5 & 7.7 & 6.3 & 4.8 & 0.4 & 0.4 & 0.02 & 106.9 \\
\hline Feb 2017 & 36.7 & 50.4 & 7.7 & 6.3 & 4.7 & 0.4 & 0.4 & 0.01 & 106.6 \\
\hline Mar 2017 & 38.6 & 53.2 & 7.9 & 6.6 & 4.9 & 0.5 & 0.4 & 0.02 & 112.0 \\
\hline Apr 2017 & 37.2 & 51.3 & 7.6 & 6.4 & 4.8 & 0.5 & 0.4 & 0.02 & 108.2 \\
\hline May 2017 & 39.1 & 54.1 & 7.9 & 6.6 & 4.9 & 0.6 & 0.4 & 0.02 & 113.7 \\
\hline June 2017 & 38.3 & 52.6 & 7.7 & 6.4 & 4.8 & 0.6 & 0.3 & 0.02 & 110.8 \\
\hline July 2017 & 38.5 & 53.2 & 7.7 & 6.4 & 4.8 & 0.7 & 0.3 & 0.01 & 111.6 \\
\hline Aug 2017 & 37.0 & 51.0 & 7.4 & 6.2 & 4.5 & 0.7 & 0.3 & 0.01 & 107.1 \\
\hline Sep 2017 & 37.5 & 51.7 & 7.4 & 6.2 & 4.5 & 0.7 & 0.3 & 0.01 & 108.2 \\
\hline Oct 2017 & 38.1 & 52.9 & 7.5 & 6.3 & 4.6 & 0.8 & 0.3 & 0.01 & 110.4 \\
\hline Nov 2017 & 43.4 & 60.1 & 8.4 & 7.0 & 5.1 & 0.9 & 0.3 & 0.02 & 125.3 \\
\hline Dec 2017 & 37.9 & 52.8 & 7.4 & 6.2 & 4.4 & 0.8 & 0.3 & 0.01 & 109.7 \\
\hline Jan 2018 & 40.8 & 56.6 & 7.9 & 6.4 & 4.6 & 0.9 & 0.3 & 0.01 & 117.5 \\
\hline Feb 2018 & 39.5 & 55.4 & 7.7 & 6.2 & 4.5 & 1.0 & 0.3 & 0.02 & 114.5 \\
\hline Mar 2018 & 39.3 & 55.4 & 7.6 & 6.2 & 4.5 & 1.0 & 0.3 & 0.01 & 114.1 \\
\hline Apr 2018 & 42.0 & 58.9 & 8.1 & 6.5 & 4.7 & 1.1 & 0.3 & 0.01 & 121.5 \\
\hline May 2018 & 40.1 & 56.2 & 7.7 & 6.1 & 4.4 & 1.0 & 0.3 & 0.01 & 115.8 \\
\hline June 2018 & 41.2 & 57.9 & 7.9 & 6.3 & 4.5 & 1.1 & 0.3 & 0.01 & 119.1 \\
\hline July 2018 & 41.8 & 69.6 & 8.5 & 6.8 & 4.8 & 1.4 & 0.3 & 0.01 & 133.3 \\
\hline Aug 2018 & 28.9 & 67.5 & 8.0 & 6.3 & 4.4 & 1.4 & 0.3 & 0.01 & 116.7 \\
\hline Sep 2018 & 27.4 & 62.0 & 7.5 & 5.9 & 4.1 & 1.3 & 0.3 & 0.01 & 108.4 \\
\hline Oct 2018 & 33.2 & 73.0 & 8.5 & 6.8 & 4.8 & 1.5 & 0.3 & 0.01 & 127.9 \\
\hline Nov 2018 & 30.8 & 76.7 & 8.8 & 7.0 & 4.8 & 1.6 & 0.3 & 0.01 & 130.0 \\
\hline Dec 2018 & 25.5 & 68.7 & 7.7 & 6.1 & 4.2 & 1.5 & 0.2 & 0.01 & 113.8 \\
\hline Jan 2019 & 32.8 & 79.4 & 8.6 & 6.9 & 4.8 & 1.7 & 0.3 & 0.01 & 134.4 \\
\hline Feb 2019 & 26.9 & 79.7 & 8.3 & 6.9 & 4.6 & 1.7 & 0.3 & 0.01 & 128.3 \\
\hline Mar 2019 & 22.1 & 74.3 & 7.6 & 6.3 & 4.2 & 1.6 & 0.2 & 0.01 & 116.5 \\
\hline Apr 2019 & 19.6 & 90.5 & 8.8 & 7.4 & 4.9 & 1.9 & 0.3 & 0.01 & 133.3 \\
\hline May 2019 & 10.0 & 101.6 & 8.9 & 7.6 & 4.9 & 2.1 & 0.2 & 0.01 & 135.3 \\
\hline June 2019 & 13.0 & 90.0 & 8.0 & 6.9 & 4.5 & 1.8 & 0.2 & 0.01 & 124.4 \\
\hline July 2019 & 17.6 & 99.2 & 9.1 & 7.7 & 5.0 & 1.9 & 0.3 & 0.01 & 140.8 \\
\hline Aug 2019 & 13.9 & 90.0 & 7.9 & 6.7 & 4.4 & 1.9 & 0.2 & 0.01 & 125.0 \\
\hline Sep 2019 & 13.9 & 91.3 & 7.9 & 6.8 & 4.4 & 1.9 & 0.2 & 0.01 & 126.4 \\
\hline Oct 2019 & 17.2 & 101.0 & 9.1 & 7.6 & 4.6 & 2.1 & 0.2 & 0.01 & 141.8 \\
\hline Nov 2019 & 18.1 & 104.4 & 9.0 & 7.8 & 2.9 & 2.2 & 0.2 & 0.01 & 144.6 \\
\hline Dec 2019 & 15.5 & 93.9 & 8.0 & 7.0 & 3.6 & 2.0 & 0.2 & 0.01 & 130.1 \\
\hline
\end{tabular}

$A R B$ angiotensin receptor blocker, DID defined daily doses per 1000 statutory health insurance-insured persons per day.

In contrast, in the US, where losartan is traditionally the most frequently used $\mathrm{ARB}$, recalled generic valsartan was primarily replaced by losartan $[22,23]$. Differences in the preferred active pharmaceutical ingredient are possibly influenced by the pharmaceutical company that had initially provided the brand marks in the 1990th or due to drug prices [24].

Our analyses suggests that only a minority of patients received new prescriptions for other ARBs than candesartan, such as losartan, telmisartan, irbesartan, olmesartan, azilsartan, or eprosartan. Similarly, the utilization of plausible alternative drugs remained unchanged suggesting that patients treated with valsartan were switched to another ARB. A change from valsartan to candesartan has the advantage of an easy estimation of the equivalent dose of candesartan (8-32 mg per day) which is roughly one-tenth of the valsartan dose. Physicians seem to prefer a change to an ARB with which they have the most experiences and/or which is broadly available on the market. Within-class 
Fig. 1 Utilization of angiotensin-II receptor blockers. Utilization of angiotensin-II receptor blockers preparations and fixed-dose combinations with

hydrochlorothiazide where included $D I D$ defined daily doses per 1000 statutory healthinsured persons per day.

Fig. 2 Ratio of the matched and candesartan. 2018-2017 ratios of matched weekdays in June and July for dispensings of valsartan and candesartan DID 1000 statutory health-insured persons per day. in DID over time; only mono daily dispensings for valsartan defined daily doses per

120

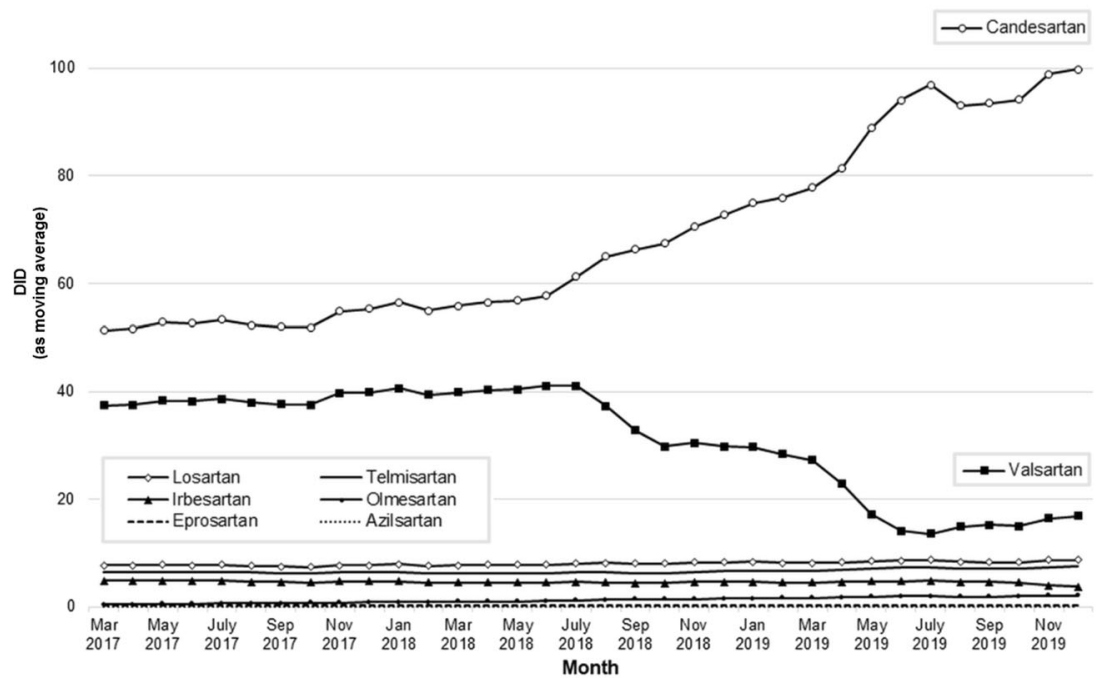

2.5
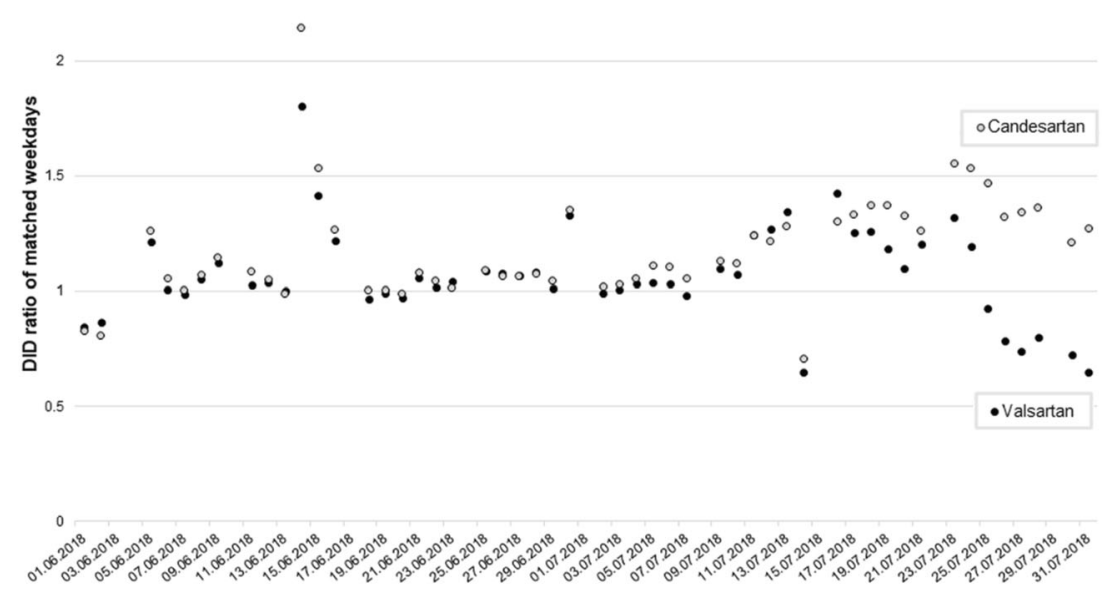

Date

Fig. 3 Unavailability of valsartan and candesartan drug products. Number of prescriptions with documented unavailability for valsartan and candesartan drug products over time; only mono preparations and fixed-dose combinations with hydrochlorothiazide were included.

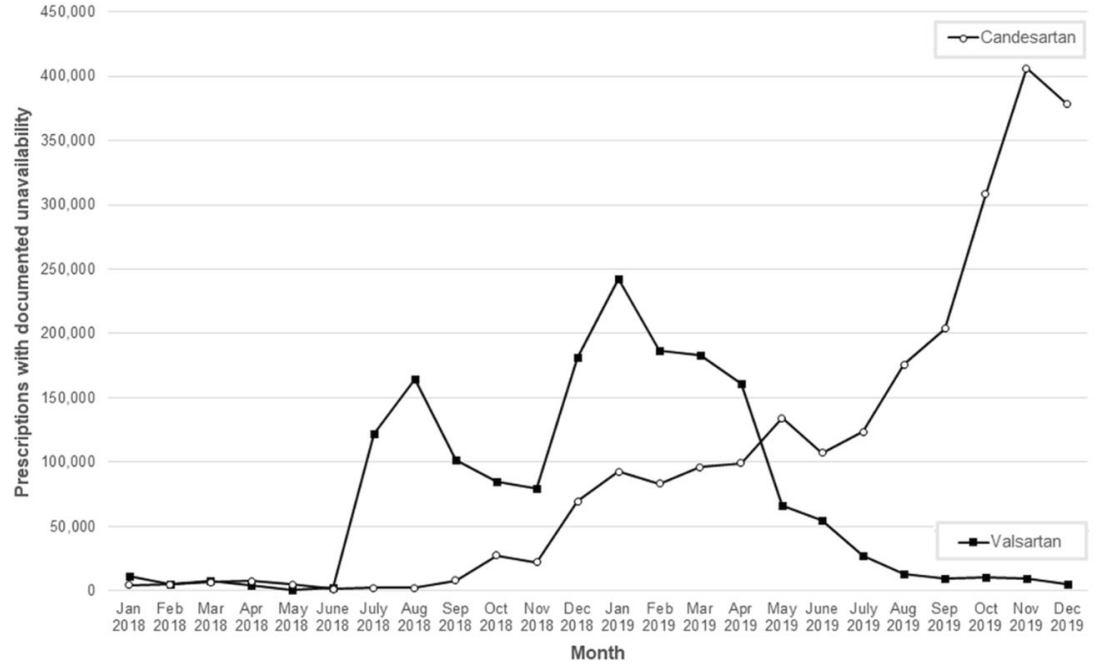


Fig. 4 Utilization of antihypertensive drugs. Utilization of antihypertensive drugs in DID over time. ACEi angiotensin-converting enzyme inhibitors, ARB angiotensin-II receptor blockers, $\mathrm{BB}$ beta blockers, CCB calcium channel blockers, DID defined daily doses per 1000 statutory healthinsured persons per day.

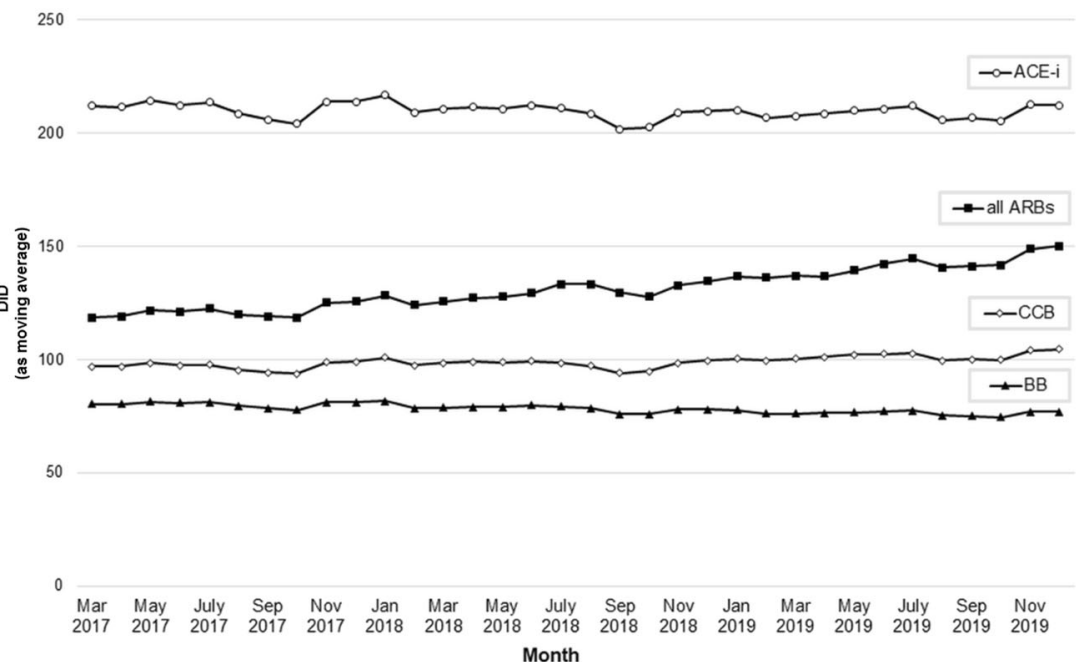

replacement of valsartan and the increase of ARBprescriptions in general seen in our study and the US suggest that physicians are convinced of the efficacy and tolerability of ARBs [21, 23-25].

After the first recall, utilization of valsartan did not decrease by the recalled $45 \%$, but by $28 \%$. About $40 \%$ of recalled valsartan might have been replaced by non-recalled valsartan. The second recall, however, led to a reduction of valsartan dispensing that exceeded the amount of the recalled products by $\sim 22 \%$. The intensified decline after several recalls and the reduction of valsartan market share of all ARBs may reflect emerging issues of drug supply and potential uncertainty with regard to additional recalls.

Recently, two studies investigated the consequences of ARB recalls in North-America [19, 23]. Analyzing a database in Ontario, Canada, covering 55,461 patients, $73.8 \%$ of recalled valsartan users switched to non-valsartan ARBs and $8.8 \%$ to a non-recalled valsartan product within one month after the recall, but $10.7 \%$ of patients did not fill an alternative medication at 3 month after the recall [19]. The lack of replacement of recalled valsartan was associated with increased healthcare utilization [19].

In a second study on 9 million generic $\mathrm{ARB}$ prescriptions in the United States, $37 \%$ of total ARB use prior to recalls was affected by recalls [23]. Generic valsartan use decreased by 53 to $10 \%$ in March 2019. Use of losartan increased after the first valsartan recalls from 67 to $73 \%$, but decreased to $71 \%$ in March 2019 following recalls of losartan [23].

These as well as our data do not allow conclusions on medication adherence or clinical outcomes. The observed slight increase of prescriptions for antihypertensives in our observation period makes it likely that the majority of patients received new prescriptions. In Germany, the health insurance companies covered the additional costs of new prescriptions of recalled or exchanged nonavailable rebated drugs.
The valsartan recalls led to unavailability of a large amount of rebated valsartan products which was followed by unavailability of rebated candesartan products [26]. It appears that these supply bottlenecks could be substituted by other generic or non-rebated drugs at least within the same quarter. In 2019, valsartan and candesartan were documented in Germany in the group of the ten most active ingredients with unavailability of rebated drugs [26]. As dispensed drug packages of ARBs rose from 2017 to 2019, it might be assumed that this did not result in a shortage of suitable ARBs in general. However, evaluation of unavailable rebated drugs has several pitfalls leading to an underestimation of the entirety of unavailable drugs [26]. For example, only those prescriptions can be counted that have been converted in the pharmacy. Drug shortages are a complex problem of growing concern and represent a constant challenge for pharmacists in everyday practice [8-10].

Two recent trends also affect utilization of cardiovascular drugs: nearly ubiquitous reliance on generic drug products and increased use of manufacturing facilities in China and India [27]. The most common reason for product recalls is manufacturing issues. An investigation of FDA drug recalls lists contamination, mislabeling, adverse reaction, defective product, and incorrect potency as common causes for recalls [28]. Other causes include regulatory issues, discontinuation of products from the market, procurement issues, business decisions and natural disasters [7]. Recalls may trigger errors, confusion and negatively impact medication adherence [29]. Recalls may also impair the relationship of the patient with physicians, pharmacists, and the health care system [30]. Drug recalls may result in change to an active ingredient of second choice, lower dosages, inaccurate use of the alternative medication, a delay or impossibility of a vitally important therapy for patients, or discontinuation of treatment [7-10]. About $60 \%$ of pharmacists surveyed in Germany reported impaired medication adherence due to drug shortages [29]. 
Impurities with nitrosamines, primarily hepatotoxic $\mathrm{N}$ nitrosodimethylamine (NDMA) and N-nitrosodiethylamine (NDEA), may occur in the manufacturing of ARBs containing a tetrazol-group (valsartan, candesartan, irbesartan, losartan, and olmesartan) [22, 31]. On 31th January 2019, the European Medicines Agency (EMA) recommended that companies producing ARBs review their manufacturing processes so that nitrosamine impurities do not develop [31]. In humans, nitrosamines were graded by the World Health Organization as probable human carcinogens due to their potential to damage DNA. For the vast majority of ARBs, nitrosamine impurities were either not found or were present at very low levels. The extrapolation of the highest possible cancer risk estimated 22 extra cases of cancer due to NDMA over the lifetimes of 100,000 patients who took valsartan from Zhejiang Huahai Pharmaceutical Co., Ltd., China-where the highest levels of impurities were found-every day for 6 years at the highest dose, and eight extra cases in 100,000 patients due to NDEA taking the medicine at the highest dose every day for 4 years. The estimates have been extrapolated from animal studies and are very low compared with the lifetime risk of cancer in the EU (1 in 2) [31]. Anyhow, exposed patients require longterm monitoring [4].

In 2018, a second large AHT class was widely discussed because of potential carcinogenic effects: Hydrochlorothiazide was reported to be dose-dependently associated with development of nonmelanoma skin cancer [32, 33]. Hydrochlorothiazide drug products were not recalled but according to a safety warning via a Dear Healthcare Professional Letter, patients had to be informed about the increased risk and the need to control their skin regularly and to use sun protection $[34,35]$. This situation likely contributed to the absence of a switch from valsartan to hydrochlorothiazide or thiazide-like diuretics. It also aggravated the overall uncertainty with regard to cardiovascular drug therapies. This is exemplified by the increased reporting of neoplasms [36].

Our study has strengths and limitations. Limitations include not having patient level information including indications for treatment and potential impact on patient outcomes. Some use of ARBs is certainly for indications other than hypertension e.g., heart failure. However, the observed increase of prescriptions of antihypertensive drugs in the observation period makes it likely that most patients received new prescriptions. The strength includes the very large and reliable sample of $>290$ million prescriptions in $\sim 88 \%$ of Germany's entire population. While for most valsartan drug products all batches were recalled, for some generic products only certain batches were affected by a recall. Due to the impossibility to differentiate between batches in valsartan products, we considered all dispensings of a product as recalled if one batch was affected by the recall. This may have resulted in a small overestimation of recalled generic valsartan but did not change the decrease of overall valsartan use or its share of all ARBs.

\section{Conclusions}

The many recalls of ARBs, primarily generic valsartan drug products from July 2018 to March 2019 due to impurities with probable carcinogenic nitrosamines led to a rapid and substantial decrease in prescriptions for valsartan. Recalled valsartan products were mainly replaced by other ARBs, predominantly candesartan. In addition, the total volume of ARB prescriptions also increased, while utilization of $\mathrm{ACEi}, \mathrm{BB}$, and CCB remained nearly unchanged.

Despite the temporal drug shortages of ARBs, our data do not suggest an under-prescribing with antihypertensive drugs during the follow-up period until the end of 2019.

\section{Summary}

\section{What is known about topic}

- In 2018, contamination of angiotensin receptor blockers (ARB) with probable carcinogenic nitrosamines resulted in more than 30 drug recalls.

- In the US, recalled valsartan was mainly replaced by losartan.

- Previous safety warnings and medication recalls were associated with gaps in prescriptions and often associated with adverse health outcomes, also due to drug shortages.

- ARB recalls were associated with increased healthcare utilization in Canada.

\section{What this study adds}

- In Germany, a within class replacement of recalled valsartan products was also found, but mainly to candesartan.

- The total volume of ARB prescriptions increased, while utilization of angiotensin converting enzyme inhibitors, betablockers, and calcium channel blockers remained nearly unchanged.

- Despite temporal drug shortages of ARBs, our data do not suggest an under-prescription with antihypertensive drugs during the follow-up period.

Funding Open Access funding enabled and organized by Projekt DEAL. 


\section{Compliance with ethical standards}

Conflict of interest UR has received scientific support and speaker honoraria from Bayer, Berlin Chemie, and Bristol Myers Squibb, all outside the submitted work. FM is supported by Deutsche Gesellschaft für Kardiologie (DGK) and has received scientific support and speaker honoraria from Bayer, Boehringer Ingelheim, Medtronic, and ReCor Medical, all outside the submitted work. FM and MB are supported by the Deutsche Forschungsgemeinschaft (SFB TRR219). UL has received speaker honoraria from Bayer, Boehringer Ingelheim, Novartis and Servier, all outside the submitted work. MS has received speaker honoraria from Novartis and Sanofi, all outside the submitted work. All other authors declare no conflict of interest.

Publisher's note Springer Nature remains neutral with regard to jurisdictional claims in published maps and institutional affiliations.

Open Access This article is licensed under a Creative Commons Attribution 4.0 International License, which permits use, sharing, adaptation, distribution and reproduction in any medium or format, as long as you give appropriate credit to the original author(s) and the source, provide a link to the Creative Commons license, and indicate if changes were made. The images or other third party material in this article are included in the article's Creative Commons license, unless indicated otherwise in a credit line to the material. If material is not included in the article's Creative Commons license and your intended use is not permitted by statutory regulation or exceeds the permitted use, you will need to obtain permission directly from the copyright holder. To view a copy of this license, visit http://creativecommons. org/licenses/by/4.0/.

\section{References}

1. Williams B, Mancia G, Spiering W, Agabiti Rosei E, Azizi M, Burnier M, et al. 2018 ESC/ESH Guidelines for the management of arterial hypertension. Eur Heart J. 2018;39:3021-3104.

2. Bundesministerium für Gesundheit. Verunreinigungen von Arzneimitteln mit Valsartan. Berlin: Bundesministerium für Gesundheit; 2018. https://kleineanfragen.de/bundestag/19/4073.

3. BfArM. Valsartan: chargenbezogener Rückruf valsartanhaltiger Arzneimittel, deren Wirkstoff von dem chinesischen Hersteller Zhejiang Huahai Pharmaceutical produziert wurde: Pressemitteilung 5/2018. Bonn, DE: BfArM; 2018. https://www.bfarm.de/Sha redDocs/Pressemitteilungen/DE/2018/pm5-2018.html.

4. Banzi R, Bertele' V. Regulatory response to contaminated valsartan. BMJ. 2018;362:k3855.

5. Byrd JB, Chertow GM, Bhalla V. Hypertension hot potatoanatomy of the angiotensin-receptor blocker recalls. N Engl J Med. 2019;380:1589-1591.

6. ABDA. Online-Nachricht: AMK: Liste der (Chargen-)Rückrufe Sartan-haltiger Arzneimittel. Berlin, DE: ABDA; 2019. https://www. abda.de/fuer-apotheker/arzneimittelkommission/amk-nachrichten/deta il/online-nachricht-amk-liste-der-chargen-rueckrufe-sartan-haltiger-a rzneimittel/.

7. Phuong JM, Penm J, Chaar B, Oldfield LD, Moles R. The impacts of medication shortages on patient outcomes: a scoping review. PloS One. 2019;14:e215837.

8. Said A, Goebel R, Ganso M, Zagermann-Muncke P, Schulz M. Drug shortages may compromise patient safety: results of a survey of the reference pharmacies of the Drug Commission of German pharmacists. Health policy. 2018;122:1302-1309.

9. Hantel A, Siegler M, Hlubocky F, Colgan K, Daugherty CK. Prevalence and severity of rationing during drug shortages: a national survey of health system pharmacists. JAMA Intern Med. 2019;179:710-711.

10. Fox ER, Sweet BV, Jensen V. Drug shortages: a complex health care crisis. Mayo Clin Proc. 2014;89:361-373.

11. Hofmann GA, Gradl G, Schulz M, Haidinger G, Tanew A, Weber B. The frequency of photosensitizing drug dispensings in Austria and Germany: a correlation with their photosensitizing potential based on published literature. J Eur Acad Dermatol Venereol. 2020;34:589-600.

12. GKV-Spitzenverband. Berichte zum Quartalsende. https://www. gkv-gamsi.de/gamsi_berichte/quartalsberichte.jsp. Berlin: 2019.

13. ABDATA Pharma data service. ABDA database and ABDA articles. Bi-Monthly Update. Eschborn: Avoxa-Mediengruppe Deutscher Apotheker GmbH; 2019.

14. German Institute of Medical Documentation and Information (DIMDI). German anatomical therapeutic chemical (ATC)-classification with defined daily doses (DDD) for Germany. Bonn, DE: German Institute of Medical Documentation and Information (DIMDI); 2019. https://www.dimdi.de/dynamic/en/drugs/atc-cla ssification/.

15. Norwegian Institute of Public Health. Use of ATC/DDD Oslo, Norway. Norwegian Institute of Public Health; 2018. https://www.whocc.no/use_of_atc_ddd/.

16. Elseviers $M$, Wettermark B, Almarsdóttir AB, Andersen $M$ Benko R, Bennie M, et al. Drug utilization research—methods and applications. Chapter 6. In: Measurement units of drug utilization. Hoboken, NJ: John Wiley \& Sons Inc. Chichester, West Sussex; 2016.

17. Federal Ministry of Health. KM6-statistics. Berlin, DE: Federal Ministry of Health; 2019. https://www. bundesgesundheitsministerium.de/themen/krankenversicherung/ zahlen-und-fakten-zur-krankenversicherung/mitglieder-undversicherte.html.

18. Gradl G, Krieg E-M, Schulz M. Evaluation of pharmaceutical concerns in Germany: frequency and potential reasons. Pharm Pract. 2016;14:786.

19. Jackevicius CA, Krumholz HM, Chong A, Koh M, Ozaki AF, Austin PC, et al. Population impact of generic valsartan recall. Circulation. 2020;141:411-413.

20. Cohn JN, Tognoni G. A randomized trial of the angiotensinreceptor blocker valsartan in chronic heart failure. N Engl J Med. 2001;345:1667-75.

21. Black HR, Bailey J, Zappe D, Samuel R. Valsartan: more than a decade of experience. Drugs. 2009;69:2393-2414.

22. Gunasekaran PM, Chertow GM, Bhalla V, Byrd JB. Current status of angiotensin receptor blocker recalls. Hypertension. 2019;74:1275-1278.

23. Desai RJ, Sarpatwari A, Gautam N, Lii J, Fischer MA, Gagne JJ. Changes in utilization of generic angiotensin receptor blockers following product recalls in the United States. JAMA. 2020; 323:87-89.

24. Grosso AM, Bodalia PN, Macallister RJ, Hingorani AD, Moon JC, Scott MA. Comparative clinical- and cost-effectiveness of candesartan and losartan in the management of hypertension and heart failure: a systematic review, meta- and cost-utility analysis. Int J Clin Pract. 2011;65:253-263.

25. Suchard MA, Schuemie MJ, Krumholz HM, You SC, Chen R, Pratt N, et al. Comprehensive comparative effectiveness and safety of first-line antihypertensive drug classes: a systematic, multinational, large-scale analysis. Lancet. 2019;394:1816-1826.

26. Gradl G. In den Jahren 2017 bis 2019 hat sich der Anteil nicht verfügbarer Rabattarzneimittel nahezu vervierfacht: DAPI number of month March 2020. Berlin: DAPI; 2020. www.dapi.de/en/new s/number-of-the-month/details/article/in-den-Jahren-2017-bis2019-hat-sich-der-anteil-nicht-verfuegbarer-rabattarzneimittel-na hezu-vervier/. 
27. Berrido AM, Byrd JB. Angiotensin receptor blockers and the risk of cancer: insights from clinical trials and recent drug recalls. Curr Hypertens Rep. 2020;22:20.

28. Hall K, Stewart T, Chang J, Freeman MK. Characteristics of FDA drug recalls: a 30-month analysis. Am J Health-Syst Pharm AJHP Off J Am Soc Health-Syst Pharmacists. 2016;73:235-240.

29. Goebel R, Ganso M, Zagermann-Muncke P, Said, A, Schulz M. Arzneimittelengpässe-Gefahr für die Patientensicherheit. Pharm Ztg. 2017;162:2065-2067.

30. McLaughlin M, Kotis D, Thomson K, Harrison M, Fennessy G, Postelnick M, et al. Effects on patient care caused by drug shortages: a survey. J Manag Care Pharm. 2013;19:783-788.

31. European medicines agency. Angiotensin-II-receptor antagonists (sartans) containing a tetrazole group: European Commission final decision: European medicines agency. Amsterdam, NL: European medicines agency; 2019. https://www.ema.europa.eu/ en/medicines/human/referrals/angiotensin-ii-receptor-antagonistssartans-containing-tetrazole-group.

32. Schulz M, Kieble M, Enners S, Laufs U, Böhm M, Kintscher U, Mahfoud F. Impact on antihypertensive prescribing after the
Dear Healthcare Professional letter on increased risk of skin cancer related to hydrochlorothiazide [abstract]. Value Health. 2020;23:102.

33. Pedersen SA, Gaist D, Schmidt SAJ, Hölmich LR, Friis S, Pottegard A. Hydrochlorothiazide use and risk of nonmelanoma skin cancer: a nationwide case-control study from Denmark. J Am Acad Dermatol. 2018;78:673-681.

34. BfArM. Rote-Hand-Brief zu Hydrochlorothiazid (HCT): Risiko von nichtmelanozytärem Hautkrebs [Basalzellkarzinom (Basaliom); Plattenepithelkarzinom der Haut (Spinaliom)]. Bonn, DE: BfArM; 2020. www.bfarm.de/SharedDocs/Risikoinforma tionen/Pharakovigilanz/DE/RHB/2018/rhb-hydrochorothiazid. html.

35. Faconti L, Ferro A, Webb AJ, Cruickshank JK, Chowienczyk PJ. Hydrochlorothiazide and the risk of skin cancer. A scientific statement of the British and Irish Hypertension Society. J Hum Hypertens. 2019;33:257-258.

36. Al-Kindi SG, Oliveira GH. Abrupt increase in reporting of neoplasms associated with valsartan after medication recall. Circ Cardiovasc Qual Outcomes. 2019;12:e05536. 